\title{
Suppression of Acute and Chronic Inflammation in
}

\section{Tumor-Bearing Rats}

\author{
John P. Brozna and Peter A. Ward, Department of Pathology, University of \\ Connecticut Health Center, Farmington, Connecticut 06032
}

\begin{abstract}
A B S T R A C T Both acute and chronic cellular inflammatory reactions were suppressed in rats bearing malignant tumors. Inhibition of the acute inflammatory reactions was demonstrated in immune complex-induced vasculitis and in the accumulation of leukocytes in subcutaneously implanted polyvinyl sponges. Suppression of chronic inflammatory reactions was demonstrated in delayed type hypersensitivity skin reactions. In spite of these suppressed reactions, dermal reactivity to vasopermeability mediators was not diminished. Neither serum complement levels nor numbers of circulating leukocytes were depressed in animals with tumors. Suppression of inflammatory reactions was paralleled by a leukotactic defect which involved both neutrophils and monocytes. This defect could be ascribed to an abnormality in the serum that rendered both cell types leukotactically defective.
\end{abstract}

\section{INTRODUCTION}

Depression of cellular inflammatory responses in patients with malignancies has been well documented $(1,2)$. However, to what extent these abnormalities are responsible for compromised ability of the host to control malignant tumors is not known. Many of the immunologic mechanisms that seem related to the control of tumor growth require the mobilization of inflammatory cells at sites of tumors. Cell-mediated immune reactions are thought to lead to the accumulation, and perhaps the activation, of a variety of inflammatory cells, particularly basophils, lymphocytes, and macrophages, the last cell type seeming to be a major participant in tumor cell destruction (3).

It is well known that adenocarcinomas of the breast which incite a mononuclear cell response (monocytes and lymphocytes) carry a considerably better prognosis than those adenocarcinomas that fail to incite inflammatory cell reactions (4). In patients with a variety of different types of solid tumors, impaired cell-mediated

Received for publication 24 November 1978 and in revised form 1 February 1979. immunity has often been associated with recurrence and(or) progression of the malignancy, whereas vigorous cellular immune reactions (whether occurring spontaneously or induced by immunotherapeutic means) have been associated with good prognosis (5).

It is possible that depressed delayed type hypersensitivity responses in tumor-bearing animals and humans are not solely the result of suppressed immune responsiveness, but also, perhaps, the result of a broad defect in the expression of inflammatory responses. Inflammation resulting from agents (such as croton oil) that do not demonstrably require immunological mechanisms for induction of inflammation has been reported to be depressed in cancer patients who are also unresponsive to the contact sensitizing agent 2,4-dinitrochlorobenzene (6). It is possible that failure to respond to the hapten could be because of defective inflammatory responsiveness rather than a suppressed cellular immune system.

In Walker tumor-bearing rats an inactivator of chemotactic factors has been found in both the homogenates of tumor cells and in the ascites fluids bathing the tumor cells (7). It was postulated that such an inactivator of chemotactic mediators might be responsible for the observations that the inflammatory response to a cotton thread implanted in vivo into a bed of connective tissue containing transplantable tumor cells is markedly depressed as compared to the thread in adjacent normal connective tissue (8). A similar suggestion has recently been made to explain the suppressed inflammatory responses in mice at sites of injected malignant cells (9).

In patients with Hodgkins disease a serum factor with chemotactic inactivator activity has been described (10). It was suggested that the anergic state in Hodgkins disease was not restricted to an abnormality in the accumulation of monocytes and lymphocytes, but was associated with an abnormality involving all inflammatory cells under leukotactic control.

Other inhibitors of leukotaxis have also been described in humans and in animals with malignant tumors. A cell-directed inhibitor of leukotaxis has been described in the sera of nearly two-thirds of patients with carcinoma 
or sarcoma (11). Cell-directed inhibitor reversibly inhibits chemotactic responsiveness of neutrophils as well as monocytes. Phagocytic uptake of radiolabeled immune precipitates (antibody-antigen complexes) by neutrophils is also suppressed by cell-directed inhibitor.

Recently, defective monocyte chemotactic function has been reported in patients with malignant tumors. This defect disappears after successful surgical treatment of the tumor. ${ }^{1}$ In studies with mice, it has been reported that the presence of tumor impairs macrophage function and suppresses inflammatory responses of the host (12). Extracts of mouse neoplasm were shown to possess a low molecular weight factor capable of inhibiting macrophage chemotaxis in vitro and when injected into normal mice, before injection of a transplantable tumor, resulted in accelerated tumor growth, presumably because of a compromise in host defense mechanism.

In this study a defect in mobilization of neutrophils in acute inflammatory reactions was found in rats with either Walker or Novikoff tumors. In addition, defective delayed type hypersensitivity responses were noted, suggesting that the anergic state in tumor-bearing animals is not limited to monocyte-lymphocyte dysfunction, but represents a broader defect in the effector limb of the inflammatory response.

\section{METHODS}

Tumors. Walker carcinosarcoma and Novikoff hepatoma cells were maintained in inbred Lewis rats (obtained from Microbiological Associates, Walkersville, Md.). Tumors were carried either in the ascites form or in the solid form, as subcutaneous tumors in extremities. Between $1-2 \times 10^{7}$ tumor cells were injected for each passage. Most of the studies to be reported employed tumors maintained in the subcutaneous (solid) form.

Reversed passive Arthus reaction. Reversed passive Arthus reactions were induced in 200 - to 225 - $g$ Lewis rats by the intravenous injection of $10 \mathrm{mg}$ of bovine serum albumin (BSA) and the intradermal injection of $100 \mu \mathrm{g}$ precipitating antibody $\mathrm{N}$ to BSA (13). The antibody preparation was obtained as the IgG fraction isolated from hyperimmune rabbit sera. The Arthus-induced premeability changes were measured by the intravenous injection of homologous rat IgG isolated from normal rat serum and radiolabeled with ${ }^{125} \mathrm{I}(14)$. Each animal received an injection of ${ }^{125} \mathrm{I}-\mathrm{IgG}\left(\cong 20 \mu \mathrm{g}\right.$ containing $\left.10^{5} \mathrm{cpm}\right)$ together with the BSA. Permeability was assessed by measuring the leakage of radiolabeled rat ${ }^{125} \mathrm{I}-\mathrm{IgG}$ into skin sites of animals bearing either Walker or Novikoff tumors. $3 \frac{1}{2} \mathrm{~h}$ after injection of the immune reactants, skin sites were removed and the amount of radioactivity in each site measured. The data were expressed as counts per skin site. This radioactivity was then related (by ratio) to the number of radioactive

\footnotetext{
${ }^{1}$ Snyderman, R., L. Meadows, W. Holder, and S. Wells. 1979. Abnormality of monocyte chemotaxis in patients with breast cancer: evidence for a tumor mediated effect. Manuscript in preparation.

${ }^{2}$ Abbreviation used in this paper: BSA, bovine serum albumin.
}

counts in $1.0 \mathrm{ml}$ of blood. The details of this technique have been reported elsewhere (15).

Analysis of hemolytic complement levels. Quantitative complement measurements were made according to methods described by Kabat and Mayer (16).

Dermal reactivity to vasopermeability factors. The ability of normal and of tumor-bearing (Walker and Novikoff tumors) rats to respond to known vasopermeability factors was observed. The animals were injected intravenously $1 / 2 \mathrm{~h}$ before skin testing with ${ }^{125} \mathrm{I}$-labeled homologous IgG. The permeability factors (purchased from Sigma Chemical Co., St. Louis, Mo.) were dissolved in phosphate-buffered saline ( $\mathrm{pH}$ 7.4) and injected intradermally into shaved paravertebral areas in the flanks. $0.1-\mathrm{ml}$ volumes used at each skin site contained the following: $5 \mu \mathrm{g}$ serotonin, $35 \mu \mathrm{g}$ bradykinin, and $5 \mu \mathrm{g}$ histamine. These amounts had been previously determined to give good permeability changes in normal rat skin. $30 \mathrm{~min}$ after injection, animals were sacrificed under ether anesthesia and individual $2.0-\mathrm{cm}$ circular areas were obtained. The amount of radioactivity was determined by gamma scintillation measurements. The permeability changes were expressed as equivalents of blood radioactivity (in $1.0 \mathrm{ml}$ ) as determined at the time of sacrifice of animals.

Leukocyte accumulation in vivo. Lewis rats without tumors or with solid Walker tumors were implanted with two polyvinyl sponge circles $(1.0 \times 0.5 \times 0.5 \mathrm{~cm})$ in the ventral subcutaneous fascial spaces of both flasks, using a $1.5-\mathrm{cm}$ midline incision. Before implantation, sponges were soaked for $15 \mathrm{~min}$ in either Hanks' salt solution or in Hanks' solution containing the bacterial chemotactic factor (a butanol extract from a culture filtrate of Escherichia coli) (17). 16 and $24 \mathrm{~h}$ after implantation, subcutaneous sponges in exsanguinated animals were surgically removed, using minimal pressure. The leukocyte content in each sponge was then assessed by gently squeezing the contents of each sponge 30-40 times in a 5-ml syringe, followed by $2-\mathrm{ml}$ washed with phosphate-buffered saline and EDTA $(0.005 \mathrm{M})$. The fluid collected was then centrifuged at $200 \mathrm{~g}$ for $10 \mathrm{~min}$ and the cell pellets resuspended in 3-ml volumes of Hanks' salt solution. The total number of leukocytes in each sponge was determined by direct counting in a hemocytometer chamber. Similar methods to assess quantitatively the cellular aspects of acute inflammatory responses are described by others (18).

Leukotaxis assessment in vitro. Chemotaxis was performed by the micropore filter technique in modified Boyden chambers (19). Filters of $5.0 \mu \mathrm{m}$ pore size (Millipore Corp., Bedford, Mass.) were used and the chemotactic activity was quantitated by counting the number of cells that had migrated to various distances from the surface monolayer in five randomly selected fields ( $\times 140$ magnification). Cells were counted at each consecutive $10 \mu \mathrm{m}$ depth beneath the monolayer and a leukotactic index was calculated in a manner similar to that described previously (11). Briefly, the total number of cells at each depth of the filter is multiplied by that distance. These products are then summed and divided by the total number of cells counted. The division yields the chemotactic index.

Various serum samples from either normal or tumor-bearing rats were tested for their effects on rat neutrophil chemotaxis by incubating various volumes $(10-100 \mu \mathrm{l})$ of the serum with $3.0 \times 10^{6}$ neutrophils (obtained from normal donors) in $0.5-\mathrm{ml}$ volumes at $37^{\circ} \mathrm{C}$ for $20 \mathrm{~min}$. The cell suspensions were then brought to $1.0-\mathrm{ml}$ volumes with medium 199 and tested in chemotactic chambers, using partially purified C5a ( $\cong 1 \mu \mathrm{g} / \mathrm{ml})$ that had been isolated from complement-activated human serum (19).

In experiments involving macrophage chemotaxis, $3 \mathrm{ml}$ of a $12 \%$ casein solution was injected intraperitoneally into Lewis rats to induce a mononuclear cell exudate. $3 \mathrm{~d}$ after the casein 
injection, the peritoneal exudate cells were harvested, washed, and placed on a Ficoll-Hypaque gradient (Pharmacia Fine Chemicals, Div. of Pharmacia Inc., Piscataway, N. J.) to obtain a pure cell suspension ( $>90 \%$ monocytes/macrophages). The cells were then washed two times with medium 199 and tested in Boyden chemotactic chambers using 8.0- $\mu \mathrm{m}$ micropore filters and partially purified C5a. Macrophage leukotaxis was assessed by counting the total number of macrophages migrating in five different oil-immersion fields.

Delayed type hypersensitivity reactions. Young adult male Lewis rats (200-225 g) were injected in one hind footpad with $0.1 \mathrm{ml}$ of BSA in complete Freund's adjuvant which had been prepared with $1 \mathrm{ml}(75 \mathrm{mg})$ BSA and $5.0 \mathrm{ml}$ complete Freund's adjuvant according to methods previously described (20). Intradermal skin challenges with $8 \mu \mathrm{g}$ BSA were performed on the shaved flanks between 10 and $18 \mathrm{~d}$ after immunization. Skin reactions were observed routinely at $3,6,15,18,24$, and $36 \mathrm{~h}$ after challenge. The reactions beginning at $6-8 \mathrm{~h}$ reached a maximum intensity between 15 and $18 \mathrm{~h}$ and persisted for 24-36 $\mathrm{h}$. The average diameters (in millimeters) of induration were determined when the reactions reached their maximum intensity (at 15-18 h). Hemorrhage was not evident grossly in the skin sites. Histological examination of fixed and stained tumor sections revealed the expected diffuse infiltrates of mononuclear cells $16 \mathrm{~h}$ after injection of antigen. In animals skin tested a second time ( $17 \mathrm{~d}$ after immunization) the intradermal injection was administered to a flank area contralateral to the prior skin test area.

\section{RESULTS}

\section{Depressed Arthus reaction in tumor-bearing rats}

As reflected by measurements of vascular damage, data in Fig. 1 show that Arthus reactions were markedly depressed in rats bearing either Walker carcinosarcoma or Novikoff hepatoma tumors. Using homologous radiolabeled gamma globulin ( $\left.{ }^{125} \mathrm{I}-\mathrm{IgG}\right)$, the permeability changes (which reflect neutrophil-dependent damage of vessels) appearing in reversed passive Arthus sites

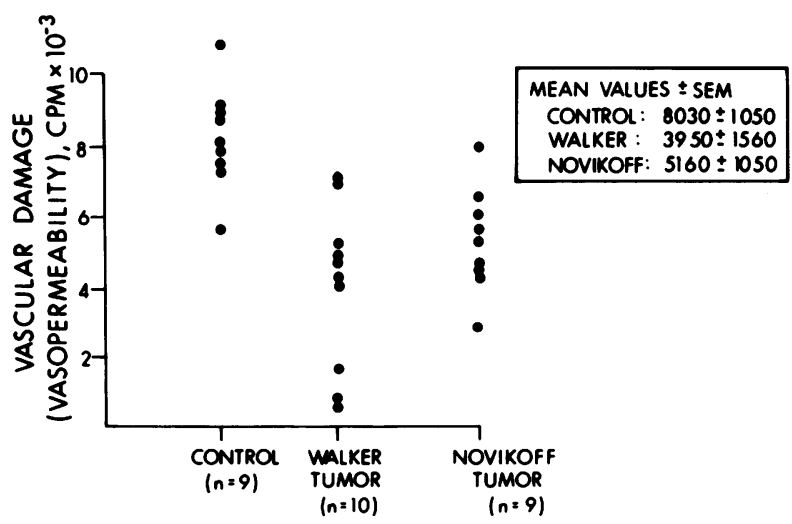

FIGURE 1 Diminished intensity of immune complex vasculitis reactions in rats with Walker-Novikoff tumors. Vascular damage was measured by leakage of radiolabeled homologous IgG. The mean values in the tumor-bearing animals are markedly depressed as compared with values in animals without tumors. See text for details. were measured in both normal animals and in animals bearing malignant tumors. The data indicate that the intensity of the Arthus reactions in tumor-bearing animals was significantly less in those reactions of control (nontumor) animals. Using the Mann-Whitney U test for nonparametric statistical analysis, the differences between the control group and either the group with the Walker tumor or the Novikoff tumor group are significant at $P<0.01$ and $<0.02$, respectively. There was, on average, a 35 and $51 \%$ reduction, respectively, in the animals with Novikoff and Walker tumors. Other parameters of the inflammatory response were also affected. In contrast to reactions in normal rats, skin sites of the cancer-bearing rats were markedly less erythematous and indurated and were free of hemorrhage. Histologically, the numbers of infiltrating neutrophils were consistently reduced in the tumorbearing animals, but the changes in permeability were the most readily quantitated parameters. On average, the intensity of the neutrophil infiltrates of Arthus reactions in normal animals was $4+$, according to previously established criteria (21). Thus, neutrophils were present in vascular walls, in the dermal connective tissue (where they were present as confluent infiltrates), and in the pericapillary areas of the layer of skeletal muscle at the dermalsubcutaneous junction. In rats with tumors, the intensity of the cellular infiltrates was distinctly reduced $(2+)$, with neutrophil infiltrates limited to perivascular areas of the dermis. Leukocytic infiltrates within the layer of skeletal muscle and diffuse interstitial infiltrates and hemorrhage were not present. As has been previously demonstrated, the bulk of permeability changes in the Arthus reaction are related to neutrophil-induced vascular damage and are not primarily a reflection of vasopermeability mediators (21).

Two additional groups of animals were compared for inhibition of the immune complex-induced vascular inflammatory reaction, using half the dose of antibody $(50 \mu \mathrm{g}$ antibody $\mathrm{N})$ in the intradermal sites. Five animals with the Walker tumor and five normal animals were compared. The mean increase in permeability change (reflecting the vascular damage) in the normal rats was $0.532 \pm 0.049$ compared with $0.346 \pm 0.065$ in the tumor (Novikoff)-bearing rats, demonstrating an inhibition of $\cong 35 \%$. Thus, inhibition of the reaction in tumor-bearing rats was roughly parallel at a lower dose of antibody.

Since it has been shown that the reversed passive Arthus reaction is dependent on both neutrophils and hemolytic complement, both peripheral blood neutrophils and hemolytic complement were measured in Walker tumor-bearing animals. It was found that the peripheral blood leukocyte count in the majority of tumor-bearing animals did not vary from normal levels $\left(10-15 \times 10^{6}\right.$ leukocytes $/ \mathrm{ml}$ of blood) and that the percentage of neutrophilic leukocytes did not differ from 
TABLE I

Hemolytic Complement Levels in Normal and Tumor-Bearing Rats

\begin{tabular}{lcc}
\hline & \multicolumn{2}{c}{$\mathrm{CH}_{\text {so }}$ levels in serum } \\
\cline { 2 - 3 } & $\begin{array}{c}\text { Sera before } \\
\text { inoculation with } \\
\text { tumor or saline }\end{array}$ & $\begin{array}{c}\text { Serum 5 d after } \\
\text { inoculation with } \\
\text { tumor or saline }\end{array}$ \\
\hline $\begin{array}{c}\text { Animals without tumor* } \\
1\end{array}$ & 10.0 & 11.0 \\
2 & 9.2 & 10.0 \\
3 & 10.5 & 10.0 \\
4 & 9.8 & 10.3 \\
Animals with tumor & & \\
5 & 10.0 & 11.0 \\
6 & 8.4 & 10.6 \\
7 & 10.0 & 10.4 \\
8 & 12.3 & 9.6 \\
9 & 10.4 & 10.2 \\
\hline
\end{tabular}

* Sensitized sheep erythrocytes were incubated with serial dilutions of either normal or tumor-bearing (Walker) rat sera at $37^{\circ} \mathrm{C}$ for $30 \mathrm{~min}$. Data shown are the number of $\mathrm{CH}_{50} \mathrm{U} / \mathrm{ml}$ of serum interpolated from complement titration curves for each sera.

normal controls $(20-30 \%$ of total leukocytes were neutrophils). However, $10 \%$ of animals with the Walker tumor showed a marked, transient leukocytosis (25-30 $\times 10^{6}$ leukocytes $/ \mathrm{ml}$ of blood).

Data shown in Table I indicate that the total hemolytic complement activity of sera from tumor-bearing rats was not depressed; if anything, the values were slightly elevated. These data would suggest that the defective reversed passive Arthus reactions in tumor-bearing rats are neither associated with reduced amounts of available serum complement nor with depressed numbers of circulating leukocytes.

\section{Cutaneous responsiveness of permeability factors in tumor-bearing rats}

As indicated by the data in Table II, the permeability changes in dermal sites induced by various permeability mediators were not depressed in rats bearing Walker or Novikoff tumors. Rats with Walker tumors were equally reactive to serotonin, bradykinin, and histamine when compared with nontumor-bearing control rats. In animals with Novikoff tumors, the reactivity to the permeability factors serotonin and histamine was $\cong 2.5$ times greater than the reactivity found in normal rats or animals with the Walker tumor. In contrast, reactivity of Novikoff tumor-bearing rats to bradykinin was not altered (Table II). Reasons for the increased reactivity in animals with Novikoff tumors to two of the three permeability agents (and also to saline injection) are not known. These data would suggest that the defect in the inflammatory response of rats with tumors is not due to a diminished reactivity of vessels to vasopermeability mediators.

\section{Defective accumulation of neutrophils in vivo}

To quantitate the ability of leukocytes from tumorbearing rats to respond in vivo to chemotactic stimuli, polyvinyl sponges presoaked either in Hanks' salt solution or in a solution of bacterial chemotactic factor were implanted subcutaneously in the flanks of normal and tumor-bearing rats. In experiments $A$ and $B$ (Table III) the results indicate that, regardless of whether or not sponges had been presoaked in chemotactic factor, twice the number of leukocytes accumulated in sponges implanted in normal animals compared with the number of leukocytes accumulating in sponges implanted in tumor-bearing animals. The differences in leukocyte accumulation in animals with and without tumor were found to be highly significant $(P \leq 0.001$ for experiment $\mathrm{A}$ and $P \leq 0.05$ for experiment $\mathrm{B}$ ). In all cases $>90 \%$ of cells were neutrophils, the remainder being monocytes.

It has been shown elsewhere that leukocyte migration into polyvinyl sponges containing only Hanks' salt solution is dependent on the availability of serum complement (18). The difference between leukocyte content in control sponges containing only Hanks' solution in normal and tumor-bearing animals probably cannot be attributed to differences in serum comple-

TABLE II

Reactions to Permeability Factors in Normal and Tumor-Bearing Rats

\begin{tabular}{lccccc}
\hline \multirow{2}{*}{$\begin{array}{c}\text { Animal } \\
\text { group }\end{array}$} & $\begin{array}{c}\text { Number } \\
\text { of animals }\end{array}$ & Saline & Serotonin & Bradykinin & Histamine \\
\cline { 3 - 6 } & & \multicolumn{4}{c}{ ml blood equivalents \pm SEM } \\
Control & 9 & $0.061 \pm 0.024$ & $0.277 \pm 0.099$ & $0.251 \pm 0.048$ & $0.097 \pm 0.049$ \\
Walker tumor & 9 & $0.054 \pm 0.032$ & $0.240 \pm 0.105$ & $0.234 \pm 0.104$ & $0.150 \pm 0.041$ \\
Novikoff tumor & 9 & $0.161 \pm 0.174$ & $0.451 \pm 0.188$ & $0.247 \pm 0.009$ & $0.247 \pm 0.156$ \\
\hline
\end{tabular}

* Data represent the ratio of radioactivity (counts per minute) in a 2-cm circular skin site divided by the amount of radioactivity in $1 \mathrm{ml}$ blood. 
TABLE III

In Vivo Leukocyte Accumulation in Polyvinyl Sponges*

\begin{tabular}{|c|c|c|c|c|c|}
\hline \multirow[b]{2}{*}{$\begin{array}{l}\text { Animal } \\
\text { number }\end{array}$} & \multicolumn{2}{|c|}{$\begin{array}{l}\text { Sponge content } \\
\text { in normal animals }\end{array}$} & \multirow[b]{2}{*}{$\begin{array}{l}\text { Animal } \\
\text { number }\end{array}$} & \multicolumn{2}{|c|}{$\begin{array}{l}\text { Sponge content } \\
\text { in tumor animals }\end{array}$} \\
\hline & Hanks' & $\begin{array}{l}\text { Bacterial } \\
\text { factor }\end{array}$ & & Hanks' & $\begin{array}{c}\text { Bacterial } \\
\text { factor }\end{array}$ \\
\hline & \multicolumn{2}{|c|}{ Leukocytes $\times 10^{-6}$} & & \multicolumn{2}{|c|}{ Leukocytes $\times 10^{-6}$} \\
\hline \multicolumn{6}{|l|}{ Experiment A } \\
\hline 1 & 3.0 & 6.6 & 8 & 1.4 & 2.9 \\
\hline 2 & 2.4 & 5.4 & 9 & 1.1 & 1.6 \\
\hline 3 & 3.6 & 3.8 & 10 & 0.7 & 2.6 \\
\hline 4 & 1.5 & 4.5 & 11 & 1.3 & 3.1 \\
\hline 5 & 2.7 & 5.5 & 12 & 3.0 & 4.3 \\
\hline 6 & 3.3 & 6.5 & 13 & 2.1 & 2.0 \\
\hline 7 & 3.0 & 4.5 & 14 & 1.0 & 3.0 \\
\hline Mean \pm SEM & $2.8 \pm 0.25$ & $5.3 \pm 0.39$ & Mean \pm SEM & $1.5 \pm 0.29$ & $2.8 \pm 0.32$ \\
\hline \multicolumn{6}{|l|}{ Experiment B } \\
\hline 1 & 12.5 & 16.1 & 5 & 3.9 & 6.6 \\
\hline 2 & 6.1 & 9.6 & 6 & 4.4 & 9.2 \\
\hline 3 & 7.3 & 12.0 & 7 & 6.5 & 5.9 \\
\hline 4 & 7.0 & 8.6 & 8 & 5.7 & 6.0 \\
\hline \multirow[t]{4}{*}{ Mean \pm SEM } & $8.2 \pm 1.94$ & $11.6 \pm 1.66$ & 9 & 4.8 & 7.1 \\
\hline & & & 10 & 6.4 & 6.1 \\
\hline & & & 11 & 3.3 & 7.4 \\
\hline & & & Mean \pm SEM & $5.0 \pm 0.46$ & $6.9 \pm 0.43$ \\
\hline
\end{tabular}

* In experiment $A$, sponges $(0.5 \mathrm{~cm}$ in diameter) were removed $24 \mathrm{~h}$ after implantation, and in experiment $B$ sponges $(0.8 \mathrm{~cm}$ in diameter) were removed $16 \mathrm{~h}$ after implantation. Differences in leukocyte accumulation ( $>90 \%$ of the cells being neutrophils) with and without tumor were found to be highly significant by the Student's $t$ test $(P \leq 0.001$ for experiment $A, P \leq 0.05$ for experiment B).

ment levels since no differences in $\mathrm{CH}_{50}$ were detected between normal and tumor-bearing rat serum (Table I). These experiments indicate that, in tumor-bearing rats, mobilization of neutrophilic leukocytes into polyvinyl sponges is defective.

\section{Depressed delayed type hypersensitivity reactions}

Two separate experiments, shown in Table IV, indicate that development of delayed type hypersensitivity reactions in rats with the Walker tumors are, as expected, totally suppressed. Rats previously immunized with BSA in complete Freund's adjuvant and challenged 10-16 d after immunization with $8 \mu \mathrm{g}$ of BSA intradermally exhibited typical delayed type hypersensitivity skin reactions. The delayed hypersensitivity reaction peaked $18 \mathrm{~h}$ after intradermal challenge. Histological examination of the indurated skin sites demonstrated leukocytic infiltrates composed mainly of mononuclear cells. These findings are consistent with delayed type hypersensitivity reactions in rats described by others (20). In no case was there histological evidence of vasculitis or hemorrhage. Induration and erythema were not detected in the first $6 \mathrm{~h}$ after intradermal challenge with antigen.

Delayed type hypersensitivity skin reactions were studied before and during the tumor-bearing period and, also, sequentially in tumor-free rats. During the 6-d interval, skin reactivity in control (nontumor bearing) rats remained unaltered (Table IV). Those animals with tumors showed total suppression grossly of the delayed type hypersensitivity skin reactions when rechallenged ( $16 \mathrm{~d}$ after immunization). Histologically, few or no inflammatory reactions appeared at sites of antigen injection.

\section{Depressed leukotactic responsiveness of leukocytes from tumor-bearing rats}

Neutrophils. To determine if neutrophils from tumorbearing animals were leukotactically defective, glycogen-induced peritoneal exudate cells from either normal rats and(or) rats with solid Walker tumors were washed and suspended in medium 199 containing 5\% normal homologous serum. The leukocyte responsiveness to 
TABLE IV

Delayed Hypersensitivity Skin Reactions in Normal and Tumor-Bearing Rats

\begin{tabular}{|c|c|c|c|c|c|}
\hline \multirow[b]{2}{*}{ Animal number } & \multicolumn{2}{|c|}{$\begin{array}{c}\text { Skin reactions } \\
\text { in tumor-free animals }\end{array}$} & \multirow[b]{2}{*}{ Animal number } & \multicolumn{2}{|c|}{$\begin{array}{c}\text { Skin reactions in } \\
\text { tumor-bearing animals* }\end{array}$} \\
\hline & Day 0 & Day 6 & & Day 0 & Day 6 \\
\hline & & & duration (mm) & & \\
\hline \multicolumn{6}{|l|}{ Experiment A } \\
\hline 1 & 13 & 15 & 8 & 17 & 0 \\
\hline 2 & 17 & 15 & 9 & 24 & 0 \\
\hline 3 & 17 & 21 & 10 & 19 & 0 \\
\hline 4 & 21 & 18 & 11 & 20 & 0 \\
\hline 5 & 20 & 17 & 12 & 21 & 0 \\
\hline 6 & 18 & 12 & 13 & 16 & 0 \\
\hline 7 & 13 & 10 & 14 & 12 & 0 \\
\hline \multirow[t]{2}{*}{ Mean $\pm S E M$} & $17.0 \pm 1.17$ & $15.4 \pm 1.39$ & 15 & 20 & 0 \\
\hline & & & Mean \pm SEM & $18.6 \pm 1.28$ & \\
\hline \multicolumn{6}{|l|}{ Experiment B } \\
\hline 1 & 10 & 16 & 6 & 13 & 0 \\
\hline 2 & 10 & 14 & 7 & 11 & 0 \\
\hline 3 & 7 & 12 & 8 & 10 & 0 \\
\hline 4 & 11 & 12 & 9 & 11 & 0 \\
\hline 5 & 11 & 5 & 10 & 11 & 0 \\
\hline \multirow[t]{3}{*}{ Mean \pm SEM } & $9.8 \pm 0.72$ & $11.8 \pm 1.85$ & 11 & 12 & 0 \\
\hline & & & 12 & 14 & 0 \\
\hline & & & Mean \pm SEM & $11.7 \pm 0.52$ & \\
\hline
\end{tabular}

* Animals were immunized with BSA $11 \mathrm{~d}$ before tumor cells $\left(2 \times 10^{7}\right)$ or phosphatebuffered saline were injected intramuscularly. Skin tests with $8 \mu \mathrm{g}$ BSA were performed 10 and $16 \mathrm{~d}$ after immunization.

the C5 chemotactic fragment was assessed in vitro. Results shown in Table $\mathrm{V}$ indicate that neutrophils from tumor-bearing animals were significantly less responsive to chemotactic stimuli when compared to neutrophils from normal animals. The average reduction was $25 \%$, which represents a highly significant fall in leukotactic responsiveness (10). The mean leukotactic index for neutrophils from normal animals was $11.2 \pm 0.46$ whereas the mean leukotactic index for neutrophils from tumor-bearing animals was $8.4 \pm 0.59$. These data demonstrate that neutrophils from tumorbearing animals are leukotactically defective.

Monocytes/macrophages. Experiments were performed to determine the leukotactic responsiveness of macrophages obtained from casein-induced peritoneal exudates in rats bearing solid tumors (Walker). Animals were injected with $5 \times 10^{6}$ tumor cells intramuscularly and $18 \mathrm{~d}$ later injected intraperitoneally with $3 \mathrm{ml}$ of $12 \%$ casein. Macrophages harvested $3 \mathrm{~d}$ after the casein injection were suspended in 5\% normal rat serum and tested for leukotactic responsiveness to the C5a fragment. Data shown in Table VI indicate that in vitro macrophage responsiveness to $\mathrm{C5}$ a was suppressed. The mean number of macrophages migrating into the filters from 10 different nontumor-bearing rats was $29.5 \pm 1.43$
TABLE V

Leukotactically Defective Neutrophils from Rats with Malignant Tumors

\begin{tabular}{ccccc}
\hline \multicolumn{2}{c}{ Neutrophils from normal rats } & & \multicolumn{2}{c}{ Neutrophils from rats with tumor } \\
\cline { 5 - 5 } Animal number & $\begin{array}{c}\text { Leukotactic } \\
\text { index* }\end{array}$ & & Animal number & $\begin{array}{c}\text { Leukotactic } \\
\text { index }\end{array}$ \\
\hline 1 & $9.7 \pm 1.0$ & & 10 & $5.7 \pm 0.6$ \\
2 & $10.0 \pm 0.0$ & & 11 & $6.2 \pm 0.6$ \\
3 & $10.2 \pm 0.3$ & & 12 & $6.2 \pm 1.7$ \\
4 & $10.5 \pm 0.1$ & & 13 & $6.8 \pm 0.4$ \\
5 & $10.9 \pm 3.0$ & & 14 & $6.9 \pm 0.4$ \\
6 & $11.3 \pm 1.0$ & & 15 & $8.6 \pm 0.1$ \\
7 & $11.9 \pm 0.0$ & & 16 & $8.7 \pm 1.2$ \\
8 & $12.7 \pm 0.9$ & & 17 & $9.0 \pm 0.5$ \\
9 & $14.0 \pm 1.0$ & & 18 & $9.4 \pm 0.4$ \\
Mean \pm SEM & $11.2 \pm 0.46$ & & 19 & $10.2 \pm 0.0$ \\
& & 20 & $11.1 \pm 0.4$ \\
& & 21 & $11.9 \pm 1.2$ \\
& & Mean \pm SEM & $8.4 \pm 0.59$
\end{tabular}

* Data are expressed as the leukotactic index, with the average difference of the mean of data from two different chemotactic chambers. All cells were suspended in 5\% normal rat serum and a C5 chemotactic fragment was used as the chemotactic attractant. 
TABLE VI

Leukotactically Defective Macrophages from Rats with Malignant Tumors

\begin{tabular}{ccccc}
\hline \multicolumn{2}{c}{ Macrophages from normal rats } & & \multicolumn{2}{c}{ Macrophages from rats with tumor } \\
\cline { 5 - 5 } Animal number & $\begin{array}{c}\text { Chemotactic } \\
\text { counts* }\end{array}$ & & Animal number & $\begin{array}{c}\text { Chemotactic } \\
\text { counts* }\end{array}$ \\
\hline 1 & $20 \pm 7$ & & 11 & $6 \pm 2$ \\
2 & $26 \pm 6$ & & 12 & $9 \pm 2$ \\
3 & $26 \pm 8$ & & 13 & $12 \pm 6$ \\
4 & $27 \pm 3$ & & 14 & $14 \pm 6$ \\
5 & $31 \pm 2$ & & 15 & $16 \pm 4$ \\
6 & $32 \pm 4$ & & 16 & $17 \pm 1$ \\
7 & $33 \pm 7$ & & 17 & $18 \pm 5$ \\
8 & $33 \pm 7$ & & 18 & $21 \pm 4$ \\
9 & $33 \pm 6$ & & 19 & $26 \pm 3$ \\
10 & $34 \pm 4$ & & 20 & $28 \pm 1$ \\
Mean \pm SEM & $29.5 \pm 1.43$ & & Mean \pm SEM & $16.7 \pm 2.20$
\end{tabular}

* Data represent the mean number of macrophages migrating in five oil-emersion fields with the average difference of the mean. Chemotactic stimulus was partly purified C5a. The mean chemotactic counts for the negative controls (absence of chemotactic stimulus) in the two groups were $5.0 \pm 2.1$ and $5.2 \pm 2.7$.

whereas the mean number of macrophages migrating into the filter from 10 different tumor-bearing rats was $16.7 \pm 2.2$, an average difference of $44 \%$. These data indicate that leukotactic responsiveness of macrophages is significantly suppressed in tumor-bearing rats $(P \leq 0.001)$.

\section{Chemotactic inhibitory effect of serum from tumor-bearing rats}

To determine if the defect in leukotactic responsiveness could be attributed to a serum abnormality, neutrophils from glycogen-induced peritoneal exudates of nontumor-bearing rats were tested for their ability to migrate chemotactically in the presence of either normal serum or serum from rats with solid Walker tumors. Normal serum was obtained from rats $2 \mathrm{~d}$ before intramuscular injection of $10^{7}$ Walker tumor cells and frozen at $-70^{\circ} \mathrm{C} .2$ wk later serum was obtained from the same animals. The 50- $\mu$ l serum samples were incubated with $3 \times 10^{6}$ rat leukocytes at $37^{\circ} \mathrm{C}$ for $20 \mathrm{~min}$ before testing in chemotactic chambers. Data shown in Table VII indicate that the presence of serum from seven normal rats bled over a 16 -d interval does not alter the average leukotactic index. In contrast, sera from eight rats obtained before and $16 \mathrm{~d}$ after intramuscular implantation of tumor clearly showed that tumor presence was related to a serum-associated depression of the leukotactic response. In seven of the eight animals the index fell between 19 and $49 \%$, with an average reduction of $30 \%$ (Table VII). The data in Tables $\mathrm{V}$ and
VII suggest that the leukotactic defect in tumor-bearing rats is an acquired leukocyte abnormality that may be related to a serum factor.

The possibility was considered that blood-derived neutrophils might reflect a different susceptibility to inhibitory effects of serum from tumor-bearing animals when compared with the exudate neutrophils described in Table VII. Accordingly, neutrophils were obtained from normal rat blood (which contained $10 \mathrm{U}$ heparin/ $\mathrm{ml}$ ) after dextran sedimentation of the erythrocytes. Aliquots of the neutrophils were then suspended in five different sera obtained from normal rats and five rats with Walker tumors. The protocol was similar to that described in Table VII. When compared with responses in normal serum, the same cells in serum from tumor-bearing rats induced the following degree of chemotactic inhibition: $66,76,56,66$, and $31 \%$, with a mean inhibition of $58.8 \pm 11.5$. These data would suggest blood derived neutrophils show a similar degree of susecptibility to chemotactic inhibition as do the cells obtained from the peritoneal exudates.

\section{Serum dose-response effect on leukotaxis}

Dose-response experiments were performed using sera from animals before and after tumor implantation. Neutrophils (peritoneal exudate) from a normal donor were used as indicator cells whereas the C5 fragment served as the attractant. As expected, with sera which had been obtained from three normal donors (Fig. 2) before tumor passage, the chemotactic response progressively improved in direct proportion to the amount of serum in the cell suspension. When the same cells were tested under the same conditions, but now with sera which had been obtained from the same animals $16 \mathrm{~d}$ after tumor passage, significant differences were noted in the effects of the sera in chemotaxis. The response of the cells in the presence of tumor-bearing sera (Fig. 2) were, in general, between 25 and $50 \%$ depressed when compared with the sera obtained before passage. The dose responses do not permit a distinction between the presence of a chemotactic inhibitor vs. the lack of a chemotactic-enhancing factor.

\section{DISCUSSION}

The data presented in this report suggest that in animals with malignant tumors there is a broad defect in expression of the inflammatory response, involving both acute and chronic cellular inflammatory reactions (Fig. 1, Table IV). Rats with malignant neoplasms not only fail to respond with delayed type inflammatory reactions to antigen (BSA), as has been reviewed elsewhere (3), but they also show depressed mobilization of neutrophils in inflammatory reactions induced by immune complexes and by the subcutaneous implantation of polyvinyl sponges (Table III). Correlated with 
TABLE VII

Development of Leukotactic (Neutrophil) Defect in Sera from Animals Bearing Solid Tumors

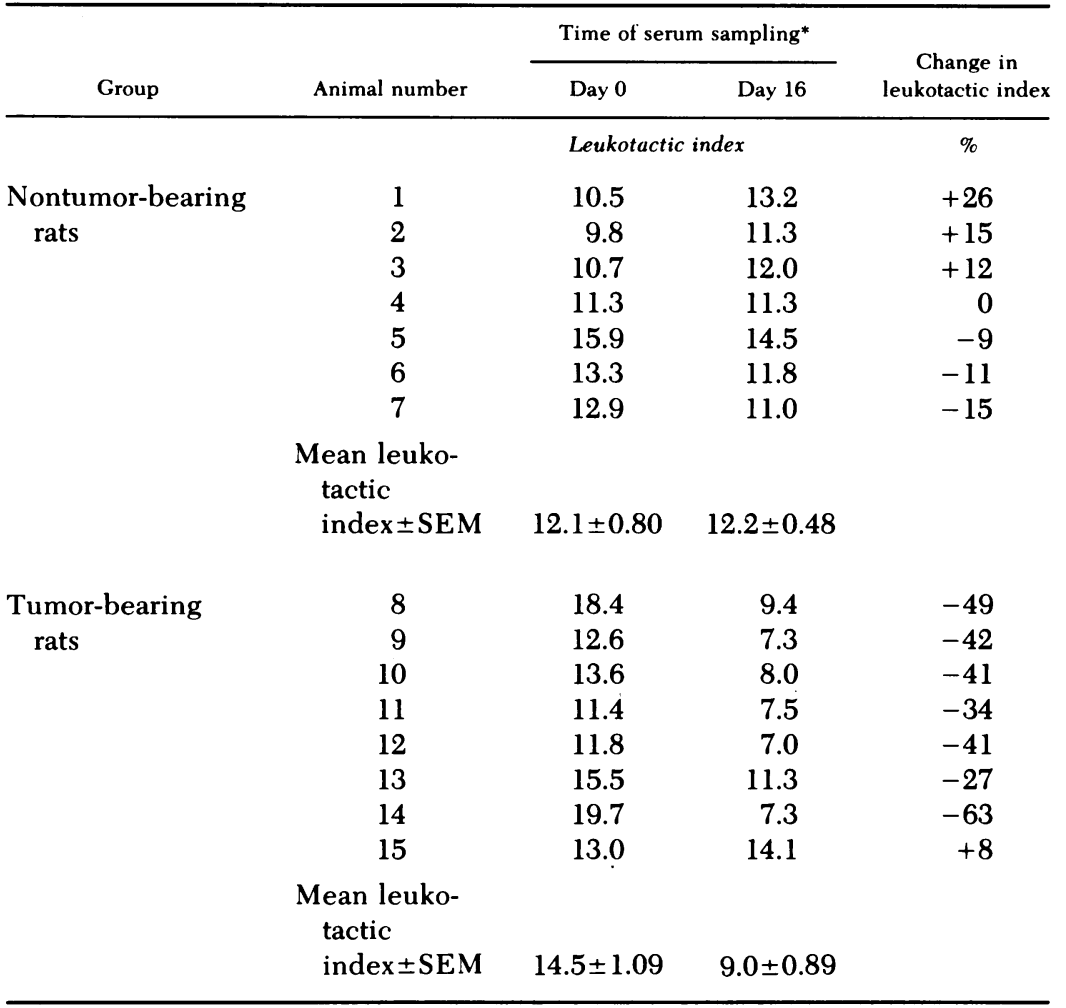

* Normal sera were collected immediately before an intramuscular injection of tumor cells $\left(5 \times 10^{6}\right)$ or saline $(0.5 \mathrm{ml})$ on day 0 ; sera were then collected $16 \mathrm{~d}$ after intramuscular injection from the same rats. Leukocytes were obtained from glycogen-induced exudates of normal rats.

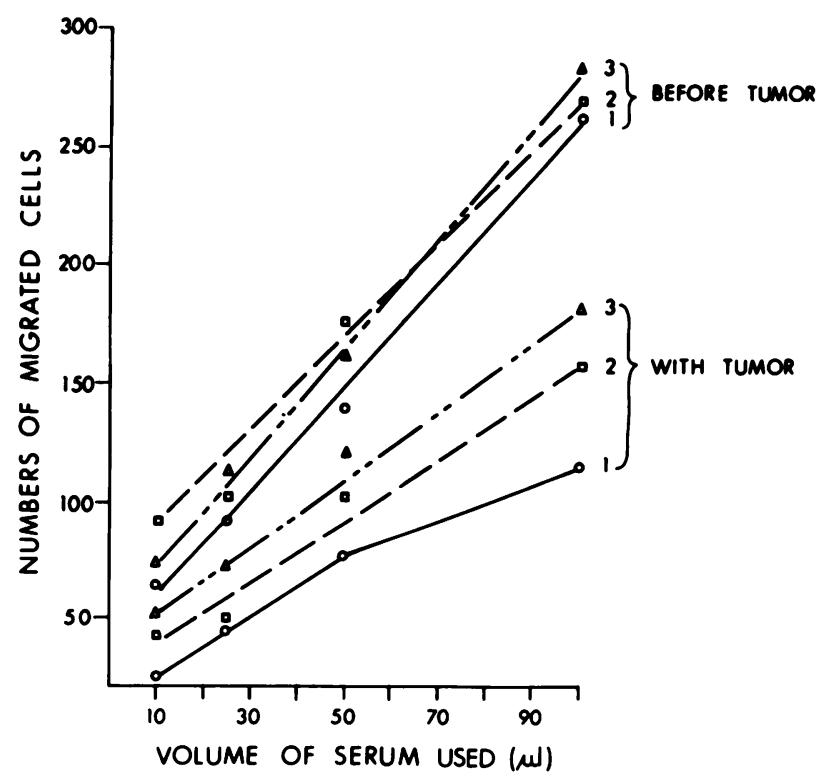

these findings are the dual defects demonstrated in vitro of leukotactic responsiveness of both neutrophils and monocytes.

Earlier studies to measure inflammatory responsiveness in cancer patients and tumor-bearing animals have emphasized the defect in delayed or contact type hypersensitivity reactions in the skin. As a result of these studies it has been postulated that acquired thymus-derived (T-cell) defects account for the observed diminished responsiveness in tumor-bearing animals, since delayed contact type hypersensitivity skin reactions are primarily T-lymphocyte dependent. However, this hypothesis does not readily explain the observa-

FIGURE 2 Inhibition of neutrophil chemotaxis by sera from tumor (Walker)-bearing rats. Peritoneal neutrophils from normal rats were examined in Boyden chambers for chemotactic responsiveness to $\mathrm{C5a}$. The data indicate that sera from each of three rats (with tumors) depressed chemotactic responsiveness, whereas sera from the same rats before tumor transfer showed no such inhibitory effect. 
tions that normal lymphocytes sensitized to specific antigen also fail to transfer delayed hypersensitivity when transferred into cancer patients, whereas in recipient patients without malignancies, this transfer is effective (22). Recent evidence that cancer patients fail to respond with inflammatory cells to nonspecific stimuli (croton oil) or to skin-sensitizing agents (dinitrochlorobenzene) suggests that there may be a generalized defect in the mobilization of inflammatory cells rather than defects that are restricted to $\mathrm{T}$ lymphocytes (6).

Several earlier studies support this hypothesis. Baum reported that polymorphonuclear leukocyte chemotactic responsiveness was impaired in patients with carcinoma and that this was indicative of poor prognosis. In contrast, in those patients with malignancies and whose neutrophil leukotactic responsiveness remained normal, this was indicative of a good prognosis (23).

In some studies an acquired defect in monocyte chemotactic responsiveness has been demonstrated in patients with malignancies. ${ }^{2}$ The suppressed monocyte leukotactic responsiveness could not be corrected by washing the cells and resuspending them in normal human serum. Only after surgical removal of the tumor did in vitro monocyte leukotactic responsiveness return to normal levels. In an extension of these studies, a factor of low molecular weight was extracted from tumor cells but not from companion normal cells. This factor impaired the in vitro chemotactic responsiveness of moncytes. When injected in vivo into tumor-bearing animals, this factor caused an acceleration in the growth of the tumor, presumably because of an effect on the host monocytes. An entirely different type of product from tumor cells with inhibitory effects on the chemotactic system is the chemotactic factor inactivator which has been found in ascitic fluids associated with malignant tumors of rats (7). Thus, at least two different inhibitors of the chemotactic system are derived from malignant cells. The studies undertaken in the present report indicate that a cell-associated defect in chemotaxis exists and that this can at least in part be explained by a serum-associated inhibitor. The fact that leukocytes from tumor-bearing rats are chemotactically defective, even after they are washed and resuspended in normal serum, and the ability to transfer the inhibition in vitro with serum, would point to a cell directed inhibitor rather than a chemotactic factor inactivator. The serum inhibitor in the present report is not further defined. Whether it is similar to the cell-directed inhibitor found in the serum of humans with malignant tumors or similar to the cell directed inhibitor extracted from experimental tumors is not known.

The observations presented in this report suggest that the inflammatory defect in tumor-bearing animals is not merely a defect in immune recognition but an expression of a generalized defect in the effector limb of the inflammatory response. This hypothesis is supported by the data presented in this paper describing a broad range of inflammatory defects.

These studies do not conflict with the established fact that immune reactivity in cancer patients can itself be defective. Lymphocyte unresponsiveness to antigenic challenge in vivo can be because of either an afferent limb or efferent limb dysfunction. The data presented in this study suggest that failure to mobilize cellular inflammatory reactions in tumor-bearing rats may be due not only to a defect in the afferent recognition limb of inflammation but to a broad range defect in the effector limb of the inflammatory response. This is an important consideration, since there is good experimental evidence that neutrophils, basophils, lymphocytes and macrophages each have, under certain experimental conditions, important cytotoxic or cytocidal activities for tumor cells (24-27). If either the afferent or efferent limb of immune system is rendered defective in an individual with a malignant tumor and (or) the ability to mobilize inflammatory cells is defective, that individual has effectively lost virtually all host defense mechanisms for combating the tumor. As such, the observations in this paper assume broad significance.

\section{ACKNOWLEDGMENT}

This work was supported in part by National Institutes of Health grant AI-09651.

\section{REFERENCES}

1. Lamb, D., F. Pilney, S. D. Kelly, and R. A. Good. 1962. A comparative study of the incidence of anergy in patients with carcinoma, leukemia, Hodgkins disease and other lymphomas. J. Immunol. 89: 555-558.

2. Eilber, F. R., and D. L. Morton. 1970. Impaired immunologic reactivity and recurrence following cancer surgery. Cancer. 25: 362-367.

3. Ward, P. A., and S. Cohen. 1977. Regulation of inflammatory responses in neoplastic disease. In Mechanism of Tumor Immunity. I. Green, S. Cohen, and R. T. McCluskey, editors. John Wiley \& Sons, New York. 305-313.

4. Berg, J. W. 1959. Inflammation and prognosis in breast cancer: a search for host resistance. Cancer Res. 12: 714-720.

5. Eilber, F. R., and D. L. Morton. 1970. Impaired immunologic reactivity and recurrence following cancer surgery. Cancer. 25: 362-367.

6. Johnson, M. W., H. I. Maibach, and S. E. Salmon. 1971. Skin reactivity in patients with cancer. Impaired delayed hypersensitivity or faulty inflammatory response? N. Engl. J. Med. 284: 1255-1257.

7. Brozna, J. P., and P. A. Ward. 1975. Antileukotactic properties of tumor cells. J. Clin. Invest. 56: 616-623.

8. Mahoney, M. J., and J. Leighton. 1962. The inflammatory response to a foreign body within transplantable tumors. Cancer Res. 22: 334-338.

9. Fauvre, R. M., B. Hevin, H. Jacob, J. A. Gaillard, and F. Jacob. 1974. Antiinflammatory effects of murine malignant cells. Proc. Natl. Acad. Sci. U.S.A. 71: 4052-4056. 
10. Ward, P. A., and J. L. Berenberg. 1974. Defective regulation of inflammatory mediators in Hodgkins disease. Supranormal levels of chemotactic factor inactivator. $N$. Engl. J. Med. 290: 76-80.

11. Maderazo, E. G., T. F. Anton, and P. A. Ward. 1978. Serum association inhibition of leukotaxis in humans with cancer. Clin. Immunol. Immunopathol. 9: 166-176.

12. Pike, M. C., and R. Snyderman. 1976. Depression of macrophage function by a factor produced by neoplasms: a mechanism for abrogration of immune surveillance. J. Immunol. 117: 1243-1249.

13. Johnson, K. J., T. P. Anderson, and P. A. Ward. 1977. Suppression of immune complex-induced inflammation by the chemotactic factor inactivator. J. Clin. Invest. 59: 951-958.

14. Helmkamp, R. W., L. R. Goodlund, W. F. Bale, I. L. Spar, and L. F. Mutschler. 1960. High specific activity iodination of $\alpha$-globulin with iodine-131 monochloride. Cancer Res. 20: 1495-1500.

15. Johnson, K. J., and P. A. Ward. 1974. Acute immunologic pulmonary alveolitis. J. Clin. Invest. 54: 1349-1357.

16. Kabat, E. A., and M. M. Mayer. 1961. In Experimental Immunochemistry. Charles C. Thomas, Publisher, Springfield, Ill. 2nd edition. 72.

17. Ward, P. A., I. H. Lepow, and L. J. Newman. 1968. Bacterial factors chemotactic for polymorphonuclear leukocytes. Am. J. Pathol. 52: 725-736.

18. Weiner, S., S. Lendvai, B. Rogers, M. Urivetzky, and E. Meilman. 1973. Nonimmune chemotaxis in vivo. Inhibition by complement depletion with cobra factor. $\mathrm{Am}$. J. Pathol. 73: 807-816.
19. Ward, P. A., R. Data, and G. Till. 1974. Regulatory control of complement derived chemotactic and anaphylatoxin mediators. In Progress in Immunology II. L. Brest and J. Holborow, editors. North-Holland Publishing Co., Amsterdam. 209-215.

20. Flax, M. H., and B. H. Waksman. 1962. Delayed cutaneous reactions in the rat. J. Immunol. 8: 496-504.

21. Ward, P. A., and C. G. Cochrane. 1965. Bound complement and immunologic injury of blood vessels. J. Exp. Med. 121: 215-234.

22. Muftuoglu, A. U., and S. Balkau. 1967. Passive transfer of tuberculin sensitivity to patients with Hodgkins disease. N. Engl. J. Med. 277: 126-129.

23. Baum, J. 1974. Chemotaxis in human disease in phagocytic cell. In Host Resistance. J. A. Bellanti and D. H. Dayton, editors. Raven Press, New York. 283-294.

24. Dvorak, A. M., A. B. Connell, K. Proppe, and H. F. Dvorak. 1978. Immunologic rejection of mammary adenocarcinoma (TA3-st) in C57 B 1/6 mice: participation of neutrophils and activated macrophages with fibrin formation. J. Immunol. 120: 1240-1248.

25. Evans, R., and P. Alexander. 1970. Co-operator of immune lymphoid cells with macrophages in tumor immunity. Nature (Lond.). 228: 620-622.

26. Churchill, W. H., W. F. Piessens, C. A. Sulis, and J. R. David. 1975. Macrophages activated as suspension cultures with lymphocyte mediators devoid of antigen become cytotoxic for tumor cells. J. Immunol. 115: 781-786.

27. Henney, C. S. 1977. Mechanisms of tumor cell destruction. In Mechanisms of Tumor Immunity. I. Green, S. Cohen, and R. T. McCluskey, editors. John Wiley \& Sons, New York. 55-86. 